\title{
Modeling Physical and Chemical Growths of Avascular Tumor
}

\author{
Changyu Liu ${ }^{1,3, *}$, Huiling $\mathrm{Li}^{2}$, Alex Hauptmann ${ }^{3}$ and Cong $\mathrm{Li}^{4}$ \\ ${ }^{1}$ School of Computer Science and Engineering, \\ South China University of Technology, Guangzhou 510006, China \\ ${ }^{2}$ State Key Laboratory of Pulp and Paper Engineering, South China University of \\ Technology, Guangzhou 510640, China \\ ${ }^{3}$ School of Computer Science, Carnegie Mellon University, \\ Pittsburgh, PA 15213, USA \\ ${ }^{4}$ College of Computer Science, Sichuan Normal University, Chengdu 610068, China \\ *yezhich@gmail.com,huiling_li@126.com,alex@cs.cmu.edu,jkxy_ld@sicnu.edu.cn

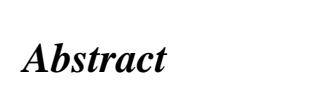 \\ Due to the avascular tumor growths were acomplex activities that involved a chemical \\ process and a physical process, a Finite Element Method (FEM) based mixture model was \\ proposed in this paper. For the chemical process, the FEM was used to solve the reaction \\ diffusion equations of three chemicals, which are the dugen, glucose and GIF, under several \\ specified boundary conditions. For the physical process, the FEM was used to solve the total \\ energy equations which can be uniquely calculated as a function of the nodal displacements \\ in the tumor. In each simulation step, we minimize the energy increment for all the tumor \\ cells. The experiment resultsdemonstrated that the proposed approach is quite efficient for \\ the modeling of avasculartumor growth
}

Keywords: FiniteElement; mixture model; tumor growth; physical; chemical

\section{Introduction}

It is well known that chere are two stages for a tumor growth [1]. The first is the avascular stage, where the cells receive nutrients from existing blood vasculature. The tumor spheroid underwent a further saturated growth after the earlier exponential growth due to the lack of nutrients. The second is the angiogenesis stage, where new blood vessels were formed by the induction of yessel chemoattractants from starving cells. It was widely considered by scientists that the whole complex process, not only from the avascular growth to angiogenesis growth, but also from the tumor invasion to the tumor deterioration, were determined by its microenvironment which could be controlled easily at the first stage than at the seconde stage. Mathematical models were firstly proposed by Thomlinson and Gray [2], which were then extended by Burton [3] and Greenspan [4]. The free boundary problems of partial differential equations were proposed by Greenspan to describe the tumor growth mechanism for earlier phase with a set of chemicals reaction diffusion equations in 1972 [4]. Based on this, many new models for tumor growth mechanism were proposed with a set of free boundary problem descriptions on partial differential equations by papers [5-7]. These models adopted a 1-D growth and a constant density for the tumor growth. Later, more sophisticated models, which included higher spatial dimensions, cell movement, cellular heterogeneity, and mechanical effects [8-9], were developed. One of them are the hybrid models, which couple together partial differential equations (PDEs) and cellular automata (CA) methods. Hybrid methods 
have been successful used to simulate fluid dynamics [10], molecular dynamics [11] and reaction diffusion systems [12].

Most of the current researches were focused mainly on the mathematic modeling and the chemical modeling of tumor growth, which did not incorporate the physical modeling. In this paper we proposed a finite element (FEM) based mixture model for tumor growth according to the existing Cellular Potts Model (CPM) [13-16], by combining a chemical modeling approach and a physical modeling approach. In chemical modeling, a FEM PDEs solver algorithm was proposed to deal with the reaction diffusion equations for three chemicals, which are the Oxygen, Glucose and the GIF. In physical modeling, a total energy equations were solved based on the traditional FEM approach. The earlier growth mechanism could be described well in our model and the experiment results showed perfectly a coherence with the measure data.

\section{Chemical Modeling}

There are mainly two kinds of chemical substances that influenced the tumor growth in its extracellular microenvironment. One of them is the nutrient which refers to oxygen and glucose. The other is the Growth Inhibitory Factor (GIF), such as vascular endothelial growth factor (VEGF), vascular permeability factor (VPE), transforming growth factor TGF beta 1 and TGF beta 2. Such influences are expressed by its localoncentrations through a set of reaction-diffusion equations. This paper proposed a newset of reaction diffusion equations, as shown in Eq. (1) and Eq. (2), based on paper [17]

$$
\begin{aligned}
& \partial \mathrm{N}(\overrightarrow{\mathrm{x}}, \mathrm{t}) / \partial \mathrm{t}=\overrightarrow{\mathrm{D}_{\mathrm{N}}} \nabla^{2} \mathrm{~N}(\overrightarrow{\mathrm{x}}, \mathrm{t})-\sigma \overrightarrow{\alpha_{\mathrm{N}}} \overrightarrow{\mathrm{K}_{\mathrm{N}}} \mathrm{N}(\overrightarrow{\mathrm{x}}, \mathrm{t})
\end{aligned}
$$

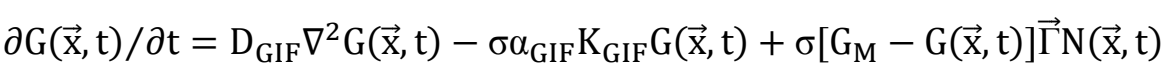

Where: $\vec{x}=(x, y, z)^{T}$ if a three dimension coordinates vector, $N(\vec{x}, t)=\left(N_{O}, N_{G}\right)^{T}$ is a concentration field vector of oxygen and glucose, $\overrightarrow{D_{N}}=\operatorname{diag}\left(D_{O}, D_{G}\right)$ is the diffusion constants diagonal matrix, $\overrightarrow{\alpha_{N}}=\operatorname{ajag}\left(\alpha_{0}, \alpha_{G}\right)$ is the control constants diagonal matrix, $\sigma$ is the tumor cell number, $\overrightarrow{\mathrm{K}_{\mathrm{N}}} \rightleftharpoons \operatorname{diag}\left(\mathrm{K}_{\mathrm{O}}, \mathrm{K}_{\mathrm{G}}\right)$ is the consumption rates diagonal matrix with $\mathrm{K}_{\mathrm{O}} \in\left\{\mathrm{K}_{\mathrm{O}}^{\mathrm{P}}, \mathrm{K}_{\mathrm{O}}^{\mathrm{Q}}, \mathrm{K}_{\mathrm{O}}^{\mathrm{N}}\right\}$ and $\mathrm{K}_{\mathrm{G}} \in\left\{\mathrm{K}_{\mathrm{G}}^{\mathrm{P}}, \mathrm{K}_{\mathrm{G}}^{\mathrm{Q}}, \mathrm{K}_{\mathrm{G}}^{\mathrm{N}}\right\}, \mathrm{G}(\overrightarrow{\mathrm{x}}, \mathrm{t})$ is the GIF concentration field, $\mathrm{D}_{\mathrm{GIF}}$ is the GIF diffusion constants $\alpha_{\mathrm{GIF}}$ is the GIF control constants diagonal matrix, $\mathrm{K}_{\mathrm{GIF}} \in$ $\left\{\mathrm{K}_{\mathrm{GIF}}^{\mathrm{P}}, \mathrm{K}_{\mathrm{GIF}}^{\mathrm{Q}}, \mathrm{K}_{\mathrm{GIF}}^{\mathrm{N}}\right\}$ is the GIF degradation rate, $\vec{\Gamma}=\left(\Gamma_{\mathrm{O}}, \Gamma_{\mathrm{G}}\right)$ is the GIF saturation rate vector, $\mathrm{G}_{\mathrm{M}}=\mathrm{G}_{\mathrm{GIF}}^{\mathrm{THR}}$ is the sakuration value. All the chemical growths are simulated with Matlab codes, as shown in Algorithm 1.

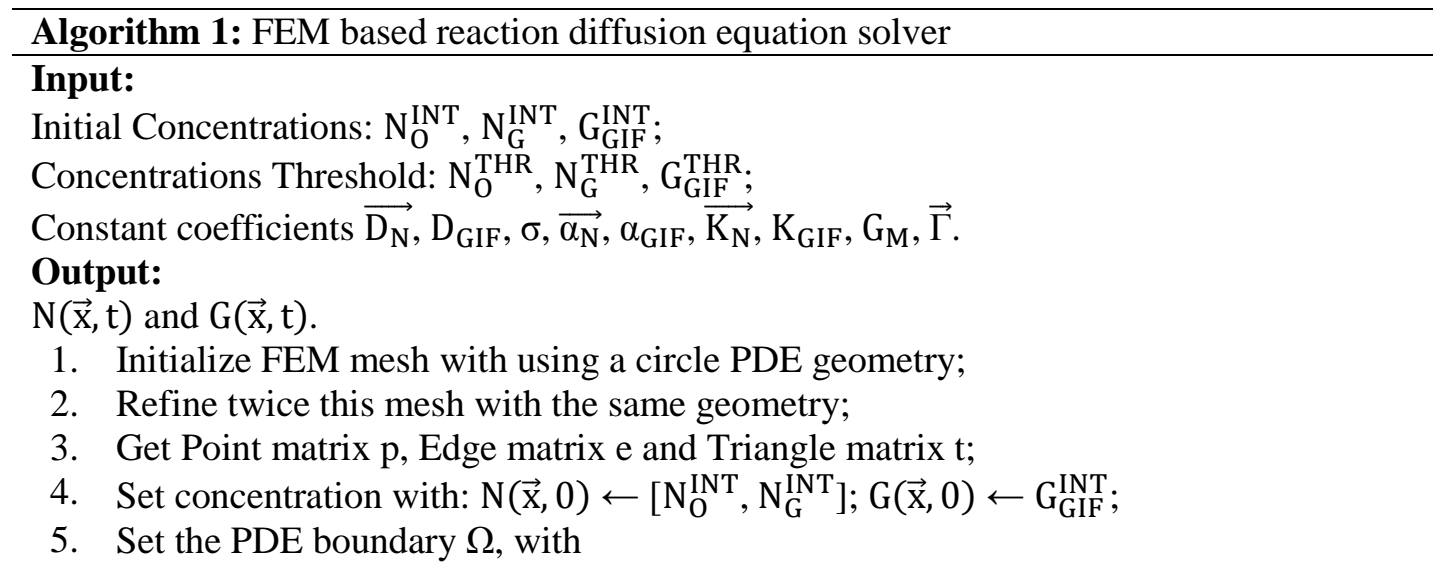




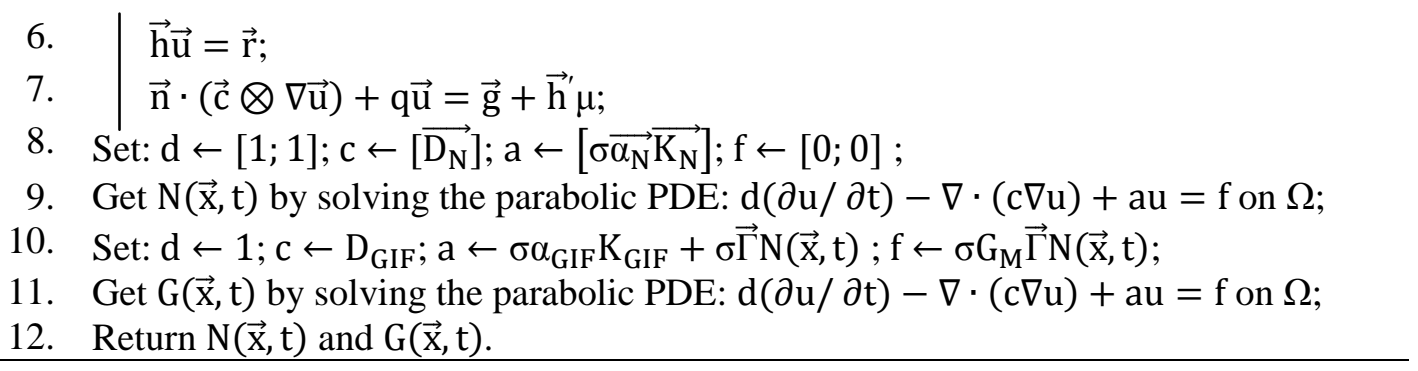

\section{Physical Modeling}

The physical growth of a tumor cell lies in the increase of cell surface and cell yolume, which can be described by the increase of its total energy. According to Jiang et al.'s [17] multi-scale avascular tumor growth model, the total energy (Hamiltonian function, H) is defined as:

$$
\mathrm{H}=\sum_{\mathrm{A}=1}^{\mathrm{AN}} \mathrm{J}_{\mathrm{A}} \mathrm{S}_{\mathrm{A}}+\sum_{\mathrm{C}=(1}^{\mathrm{CN}} \gamma\left(\mathrm{V}_{\mathrm{C}}-\mathrm{V}_{\mathrm{C}}^{*}\right)^{2}
$$

Where: $\mathrm{H}$ (Hamiltonian function) is an effective total energy, AN/1s the global total mesh

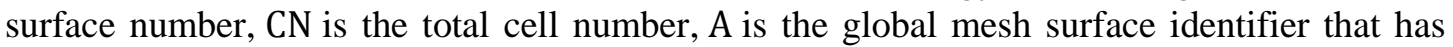
value among $1 \sim \mathrm{AN}, \mathrm{C}$ is the cell identifier that has value among $1 \sim \mathrm{CN}, \mathrm{S}_{\mathrm{A}}$ is the current area of mesh surface $A, V_{C}$ is the current volume of cell $C$ while $V_{C}^{*}$ is its target cell volume, $J_{A}$ is the adhesive coefficient between mesh surface $A$ and its neighbors, $\gamma$ is the coefficient corresponding to the elasticity of the cell volume of $C$. In this model, the total energy change $\mathrm{H}$ of a tumor cell was determined by its surface and volume. Let the change of energy be $\Delta \mathrm{H}$. According to the total energy Eq. (3), we could obtain the Eq. (4), as:

$$
\begin{gathered}
\Delta \mathrm{H}=\sum_{\mathrm{A}=1}^{\mathrm{AN}} \mathrm{J}_{\mathrm{A}}\left(\mathrm{S}_{\mathrm{A}}+\mathrm{dS}_{\mathrm{A}}\right)+\sum_{\mathrm{C}=1}^{\mathrm{CN}}\left(\mathrm{V}_{\mathrm{C}}+\mathrm{dV}_{\mathrm{C}}-\mathrm{V}_{\mathrm{C}}^{*}\right)^{2}-\sum_{\mathrm{A}=1}^{\mathrm{AN}} \mathrm{J}_{\mathrm{A}} \mathrm{S}_{\mathrm{A}}-\sum_{\mathrm{C}=1}^{\mathrm{CN}} \gamma\left(\mathrm{V}_{\mathrm{C}}-\mathrm{V}_{\mathrm{C}}^{*}\right)^{2} \\
=\sum_{\mathrm{A}=1}^{\mathrm{AN}} \mathrm{J}_{\mathrm{A}} \mathrm{dS}_{\mathrm{A}}+\sum_{\mathrm{C}=1}^{\mathrm{CN}} \gamma\left(\mathrm{dV}_{\mathrm{C}}\right)^{2}-\sum_{\mathrm{j}=1}^{\mathrm{CN}} 2 \gamma \cdot \mathrm{dV} \mathrm{V}_{\mathrm{C}} \cdot\left(\mathrm{V}_{\mathrm{C}}^{*}-\mathrm{V}_{\mathrm{C}}\right)
\end{gathered}
$$

In the finite erement model, the change of the energy can be uniquely determined by the nodal displacement $\{\mathrm{u}\}$. The $\mathrm{ain}$ of this finite element analysis is to find the most reasonable displacement $\{\mathrm{u}\}$ that leads to minimum $\Delta \mathrm{H}$. One tumor cell will reach a critical point for division, if meets

$$
\partial(\Delta \mathrm{H}) / \partial(\{\mathrm{u}\})=0
$$

The physical growth of a tumor cell is actual to obtain the nodal displacement $\{\mathrm{u}\}$ from Eq. (5). In orde to get $\Delta \mathrm{H}$ from Eq. (4), we should know firstly how to compute the value of $\mathrm{dS}_{\mathrm{A}}$ and $\mathrm{dV}_{\mathrm{C}}$ by $\mathrm{using}$ the Finite Element method. According to the paper [18], the area increment dS an be calculated by,

$$
\mathrm{dS}_{\mathrm{A}}=\mathrm{dS}_{\mathrm{AL}_{-} \mathrm{C}}=\{\mathrm{u}\}_{\mathrm{AL}_{-} \mathrm{C}}^{\mathrm{T}}\left\{\mathrm{F}_{\mathrm{S}}\right\}_{\mathrm{AL}_{-} \mathrm{C}}+\{\mathrm{u}\}_{\mathrm{AL}_{-} \mathrm{C}}^{\mathrm{T}}\left[\mathrm{K}_{\mathrm{S}}\right]_{\mathrm{AL}_{-} \mathrm{C}}\{\mathrm{u}\}_{\mathrm{AL}_{-} \mathrm{C}}
$$

Where: $\{\mathrm{u}\}=\left\{\mathrm{d} \overrightarrow{r_{1}}, \mathrm{~d} \overrightarrow{r_{2}}, d \overrightarrow{r_{3}}\right\}^{T}$ is a vertex displacement vector or nodal displacement vector, $\mathrm{d} \overrightarrow{r_{1}}, d \overrightarrow{r_{2}}$ and $d \overrightarrow{r_{3}}$ are three differential vectors for the vertex displacements with $d \overrightarrow{r_{1}}=$ $\left\{\mathrm{u}_{1}, \mathrm{v}_{1}, \mathrm{w}_{1}\right\}^{\mathrm{T}}, \mathrm{d} \overrightarrow{\mathrm{r}_{2}}=\left\{\mathrm{u}_{2}, \mathrm{v}_{2}, \mathrm{w}_{2}\right\}^{\mathrm{T}}$ and $\mathrm{dr}_{3}=\left\{\mathrm{u}_{3}, \mathrm{v}_{3}, \mathrm{w}_{3}\right\}^{\mathrm{T}},\left\{\mathrm{F}_{\mathrm{S}}\right\}$ can be regarded as a tumor surface growth driving force, $\left[\mathrm{K}_{\mathrm{S}}\right]=\frac{1}{2}\left(\left[\mathrm{~K}_{\mathrm{S}}^{*}\right]+\left[\mathrm{K}_{\mathrm{S}}^{*}\right]^{\mathrm{T}}\right)$ can be regarded as a tumor surface growth stiffness matrix, they are defined as: 


$$
\left\{\mathrm{F}_{\mathrm{S}}\right\}=\frac{1}{4 \mathrm{~S}}\left\{\mathrm{~F}_{\mathrm{S} 1}, \mathrm{~F}_{\mathrm{S} 2}, \mathrm{~F}_{\mathrm{S} 3}, \mathrm{~F}_{\mathrm{S} 4}, \mathrm{~F}_{\mathrm{S} 5}, \mathrm{~F}_{\mathrm{S} 6}, \mathrm{~F}_{\mathrm{S} 7}, \mathrm{~F}_{\mathrm{S} 8}, \mathrm{~F}_{\mathrm{S} 9}\right\}^{\mathrm{T}} \text { and }\left[\mathrm{K}_{\mathrm{S}}^{*}\right]=\frac{1}{4 \mathrm{~S}}\left[\begin{array}{lll}
{[0]} & {[\mathrm{k}]} & {[0]} \\
{[0]} & {[0]} & {[\mathrm{k}]} \\
{[\mathrm{k}]} & {[0]} & {[0]}
\end{array}\right]
$$

With:

$$
\begin{aligned}
& \mathrm{F}_{\mathrm{S} 1}=(\overrightarrow{\mathrm{b}} \cdot \overrightarrow{\mathrm{b}}) \mathrm{r}_{1 \mathrm{x}}+(\overrightarrow{\mathrm{b}} \cdot \overrightarrow{\mathrm{c}}) \mathrm{r}_{2 \mathrm{x}}+(\overrightarrow{\mathrm{b}} \cdot \overrightarrow{\mathrm{a}}) \mathrm{r}_{3 \mathrm{x}}, \mathrm{F}_{\mathrm{S} 2}=(\overrightarrow{\mathrm{b}} \cdot \overrightarrow{\mathrm{b}}) \mathrm{r}_{1 \mathrm{y}}+(\overrightarrow{\mathrm{b}} \cdot \overrightarrow{\mathrm{c}}) \mathrm{r}_{2 \mathrm{y}}+(\overrightarrow{\mathrm{b}} \cdot \overrightarrow{\mathrm{a}}) \mathrm{r}_{3 \mathrm{y}}, \\
& \mathrm{F}_{\mathrm{S} 3}=(\vec{b} \cdot \vec{b}) \mathrm{r}_{1 \mathrm{z}}+(\overrightarrow{\mathrm{b}} \cdot \overrightarrow{\mathrm{c}}) \mathrm{r}_{2 \mathrm{z}}+(\overrightarrow{\mathrm{b}} \cdot \overrightarrow{\mathrm{a}}) \mathrm{r}_{3 \mathrm{z}}, \mathrm{F}_{\mathrm{S} 4}=(\overrightarrow{\mathrm{c}} \cdot \overrightarrow{\mathrm{b}}) \mathrm{r}_{1 \mathrm{x}}+(\overrightarrow{\mathrm{c}} \cdot \overrightarrow{\mathrm{c}}) \mathrm{r}_{2 \mathrm{x}}+(\overrightarrow{\mathrm{c}} \cdot \overrightarrow{\mathrm{a}}) \mathrm{r}_{3 \mathrm{x}}, \\
& \mathrm{F}_{\mathrm{S} 5}=(\overrightarrow{\mathrm{c}} \cdot \overrightarrow{\mathrm{b}}) \mathrm{r}_{1 \mathrm{y}}+(\overrightarrow{\mathrm{c}} \cdot \overrightarrow{\mathrm{c}}) \mathrm{r}_{2 \mathrm{y}}+(\overrightarrow{\mathrm{c}} \cdot \overrightarrow{\mathrm{a}}) \mathrm{r}_{3 \mathrm{y}}, \mathrm{F}_{\mathrm{S} 6}=(\overrightarrow{\mathrm{c}} \cdot \overrightarrow{\mathrm{b}}) \mathrm{r}_{1 \mathrm{z}}+(\overrightarrow{\mathrm{c}} \cdot \overrightarrow{\mathrm{c}}) \mathrm{r}_{2 \mathrm{z}}+(\overrightarrow{\mathrm{c}} \cdot \overrightarrow{\mathrm{a}}) \mathrm{r}_{3 \mathrm{z}}, \\
& \mathrm{F}_{S 7}=(\overrightarrow{\mathrm{a}} \cdot \overrightarrow{\mathrm{b}}) \mathrm{r}_{1 \mathrm{x}}+(\overrightarrow{\mathrm{a}} \cdot \overrightarrow{\mathrm{c}}) \mathrm{r}_{2 \mathrm{x}}+(\overrightarrow{\mathrm{a}} \cdot \overrightarrow{\mathrm{a}}) \mathrm{r}_{3 \mathrm{x}}, \mathrm{F}_{\mathrm{S} 8}=(\overrightarrow{\mathrm{a}} \cdot \overrightarrow{\mathrm{b}}) \mathrm{r}_{1 \mathrm{y}}+(\overrightarrow{\mathrm{a}} \cdot \overrightarrow{\mathrm{c}}) \mathrm{r}_{2 \mathrm{y}}+(\overrightarrow{\mathrm{a}} \cdot \overrightarrow{\mathrm{a}}) \mathrm{r}_{3 y}, \\
& \mathrm{~F}_{\mathrm{S} 9}=(\overrightarrow{\mathrm{a}} \cdot \overrightarrow{\mathrm{b}}) \mathrm{r}_{1 \mathrm{z}}+(\overrightarrow{\mathrm{a}} \cdot \overrightarrow{\mathrm{c}}) \mathrm{r}_{2 \mathrm{z}}+(\overrightarrow{\mathrm{a}} \cdot \overrightarrow{\mathrm{a}}) \mathrm{r}_{3 \mathrm{z}}, \\
& {[\mathrm{k}]=\overrightarrow{\mathrm{r}_{1}} \overrightarrow{\mathrm{r}_{2}}+\overrightarrow{\mathrm{r}_{2}} \overrightarrow{\mathrm{r}_{3}}+\overrightarrow{\mathrm{r}_{3} \mathrm{r}_{1}}-\overrightarrow{\mathrm{r}_{2}} \overrightarrow{r_{1}}-\overrightarrow{r_{3}} \overrightarrow{r_{2}}-\overrightarrow{\mathrm{r}_{1} \mathrm{r}_{3}} \text {. }}
\end{aligned}
$$

According to the paper [18], the volume increment dV can be calculated by,

$$
\mathrm{dV}_{\mathrm{A}}=\mathrm{dV}_{\mathrm{AL}_{-} \mathrm{C}}=\{\mathrm{u}\}_{\mathrm{AL}_{-} \mathrm{C}}^{\mathrm{T}}\left\{\mathrm{F}_{\mathrm{V}}\right\}_{\mathrm{AL}-\mathrm{C}}+\{\mathrm{u}\}_{\mathrm{AL}_{-} \mathrm{C}}^{\mathrm{T}}\left[\mathrm{K}_{\mathrm{V}}\right]_{\mathrm{AL} \mathrm{L}_{-} \mathrm{C}}\{\mathrm{u}\}_{\mathrm{AL}_{-} \mathrm{C}}
$$

Where: $\{\mathrm{u}\}$ is a nodal displacement vector, $\left\{\mathrm{F}_{V}\right\}$ can be tegarded as a tumor volume growth driving force, $\left[\mathrm{K}_{\mathrm{V}}\right]=\frac{1}{2}\left(\left[\mathrm{~K}_{\mathrm{V}}^{*}\right]+\left[\mathrm{K}_{\mathrm{V}}^{*}\right]^{\mathrm{T}}\right)$ dan be regarded as a tumor volume growth stiffness matrix, they are defined as:

$$
\left\{\mathrm{F}_{\mathrm{V}}\right\}=\frac{1}{6}\left\{\mathrm{~F}_{\mathrm{V} 1}, \mathrm{~F}_{\mathrm{V} 2}, \mathrm{~F}_{\mathrm{V} 3}, \mathrm{~F}_{\mathrm{V} 4}, \mathrm{~F}_{\mathrm{V} 5}, \mathrm{~F}_{\mathrm{V} 6}, \mathrm{~F}_{\mathrm{V}}, \mathrm{F}_{\mathrm{V} 8}, \mathrm{~F}_{\mathrm{V} 9}\right\}^{\mathrm{T}} \text { and }\left[\mathrm{K}_{\mathrm{V}}^{*}\right]=\frac{1}{6}\left[\begin{array}{ccc}
{[0]} & {[0]} & {\left[\mathrm{K}_{\mathrm{V}}^{3}\right]} \\
{\left[\mathrm{K}_{\mathrm{V}}^{1}\right]} & {[0]} & {[0]} \\
{[0]} & {\left[\mathrm{K}_{\mathrm{V}}^{2}\right]} & {[0]}
\end{array}\right]
$$

With:

$$
\begin{aligned}
& F_{V 1}=r_{2 y} r_{3 z}-r_{2 z} r_{3 y}, F_{V 2}=r_{2 z} r_{3 x}-r_{2 x} r_{3 z}, F_{V 3}=r_{2 x} r_{3 y}-r_{2 y} r_{3 x} \text {, } \\
& F_{V 4}=r_{3 y} r_{1 z}-r_{3 z} y_{1 y}, F_{V 5}=r_{3 z} r_{1 x}-r_{3 x} r_{1 z}, F_{V 6}=r_{3 x} r_{1 y}-r_{3 y} r_{1 x} \text {, } \\
& \mathrm{F}_{\mathrm{V} 7}=\mathrm{r}_{1 \mathrm{y}} \mathrm{r}_{2 \mathrm{z}}-\mathrm{r}_{1 \mathrm{z}} \mathrm{r}_{2 \mathrm{y}}, \mathrm{F}_{\mathrm{V} 8}=\mathrm{r}_{1 \mathrm{z}} \mathrm{r}_{2 \mathrm{x}}-\mathrm{r}_{1 \mathrm{x}} \mathrm{r}_{2 \mathrm{z}}, \mathrm{F}_{\mathrm{V} 9}=\mathrm{r}_{1 \mathrm{x}} \mathrm{r}_{2 \mathrm{y}}-\mathrm{r}_{1 \mathrm{y}} \mathrm{r}_{2 \mathrm{x}} \text {, } \\
& {\left[\mathrm{K}_{\mathrm{V}}^{1}\right]=\overrightarrow{\mathrm{a}_{1}}+\overrightarrow{\mathrm{j}} \overrightarrow{\mathrm{b}_{1}}+\overrightarrow{\mathrm{k}_{1}} \overrightarrow{\mathrm{c}_{1}}, \overrightarrow{\mathrm{a}_{1}}=\left\{0,-\mathrm{r}_{1 \mathrm{z}}, \mathrm{r}_{1 \mathrm{y}}\right\}^{\mathrm{T}}, \overrightarrow{\mathrm{b}_{1}}=\left\{-\mathrm{r}_{1 \mathrm{z}}, 0, \mathrm{r}_{1 \mathrm{x}}\right\}^{\mathrm{T}}, \overrightarrow{\mathrm{c}_{1}}=\left\{-\mathrm{r}_{1 \mathrm{y}}, \mathrm{r}_{1 \mathrm{x}}, 0\right\}^{\mathrm{T}},} \\
& {\left[\mathrm{K}_{\mathrm{V}}^{2}\right]=\overrightarrow{\mathrm{ia}_{2}}+\overrightarrow{\mathrm{j}_{2}}+\overrightarrow{\mathrm{k}} \overrightarrow{\mathrm{c}_{2}}, \overrightarrow{\mathrm{a}_{2}}=\left\{0,-\mathrm{r}_{2 \mathrm{z}}, \mathrm{r}_{2 \mathrm{y}}\right\}^{\mathrm{T}}, \overrightarrow{\mathrm{b}_{2}}=\left\{-\mathrm{r}_{2 \mathrm{z}}, 0, \mathrm{r}_{2 \mathrm{x}}\right\}^{\mathrm{T}}, \overrightarrow{\mathrm{c}_{2}}=\left\{-\mathrm{r}_{2 \mathrm{y}}, \mathrm{r}_{2 \mathrm{x}}, 0\right\}^{\mathrm{T}} \text {, }} \\
& \left.\left[\mathrm{K}^{3}\right]=\overrightarrow{\mathrm{v}}\right] \overrightarrow{\mathrm{a}_{3}}+\overrightarrow{\mathrm{j}} \overrightarrow{\mathrm{b}_{3}}+\overrightarrow{\mathrm{k}} \overrightarrow{\mathrm{c}_{3}}, \overrightarrow{\mathrm{a}_{3}}=\left\{0,-\mathrm{r}_{3 \mathrm{z}}, \mathrm{r}_{3 y}\right\}^{\mathrm{T}}, \overrightarrow{\mathrm{b}_{3}}=\left\{-\mathrm{r}_{3 \mathrm{z}}, 0, \mathrm{r}_{3 \mathrm{x}}\right\}^{\mathrm{T}}, \overrightarrow{\mathrm{c}_{3}}=\left\{-\mathrm{r}_{3 y}, \mathrm{r}_{3 \mathrm{x}}, 0\right\}^{\mathrm{T}} \text {. }
\end{aligned}
$$

Finally, Eq. (5) can be rewritten as,

$$
[\mathrm{K}]\{\mathrm{u}\}=\{\mathrm{F}\}
$$

Subject to: $[\mathrm{K}]=\sum_{\mathrm{A}=1}^{\mathrm{AN}} \mathrm{J}_{\mathrm{A}}\left[\mathrm{K}_{\mathrm{S}}\right]_{\mathrm{A}}+\sum_{\mathrm{C}=1}^{\mathrm{CN}} \gamma\left\{\mathrm{F}_{\mathrm{V}}\right\}_{\mathrm{C}}\left\{\mathrm{F}_{\mathrm{V}}\right\}_{\mathrm{C}}^{\mathrm{T}}-\sum_{\mathrm{C}=1}^{\mathrm{CN}} 2 \gamma\left(\mathrm{V}_{\mathrm{C}}^{*}-\mathrm{V}_{\mathrm{C}}\right)\left[\mathrm{K}_{\mathrm{V}}\right]_{\mathrm{C}}$,

$$
\{\mathrm{F}\}=\sum_{\mathrm{C}=1}^{\mathrm{CN}} \gamma\left(\mathrm{V}_{\mathrm{C}}^{*}-\mathrm{V}_{\mathrm{C}}\right)\left[\mathrm{F}_{\mathrm{V}}\right]_{\mathrm{C}}-(1 / 2) \sum_{\mathrm{A}=1}^{\mathrm{AN}} \mathrm{J}_{\mathrm{A}}\left[\mathrm{F}_{\mathrm{S}}\right]_{\mathrm{A}} \text {. }
$$


All the physical growths are simulated with $\mathrm{C}++$ codes, as shown in Algorithm 2.

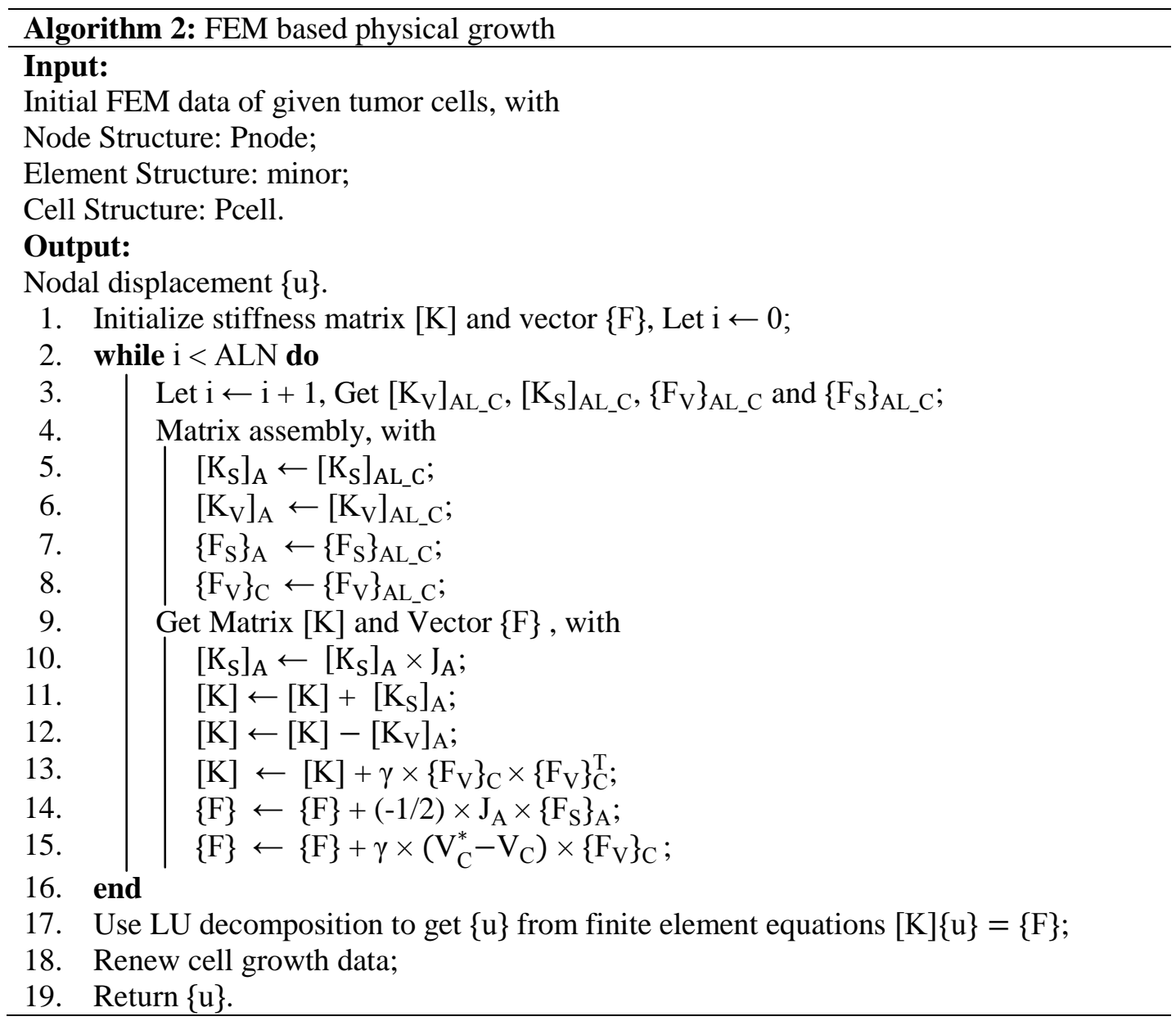

\section{Experiments}

\subsection{Physical Modeling Results}

There are three key steps for a FEM based physical modeling of tumor growth, which are the nodes selection, the mesh partition and the matrix assembly. The first step is the nodes selection.The base of the FEM is the Element, which consisted of all simulated nodes. In the primary stage of tumor growth, it has only one single cell, which can be regarded as a sphere where we can obtain all needed nodes. Then, a mesh partition was proceeded to select three sequential nodes as triangle vertices with Delaunay triangulation algorithm after the nodes selection according to the right hand rule. Being able to ensure an empty circle characteristic that any four nodes don't not share a same circle, the Delaunay triangulation algorithm was used widely in mesh partition. In this paper, a Bowyer Watson algorithm which is a kind of Delaunay triangulation algorithms was adopted. A tetrahedron will be obtained to compute its surface area as well as volume and the nodes offsets will be got to simulate the tumor growth with the total energy equations after nodes selection and mesh partition. All the physical growths are simulated under parameters: radius $=11.2725 \mu \mathrm{m}$, node number $=152$, mesh number $=300$, center $=$ origin, and status $=P$. Then, introduce these initial data to simulate 
the physical tumor growth. Figure 1(a) showed the initial tumor cell at the origin. Figure 1(bc) showed two daughter cells of the initial tumor cell after a FEM based tumor growth.

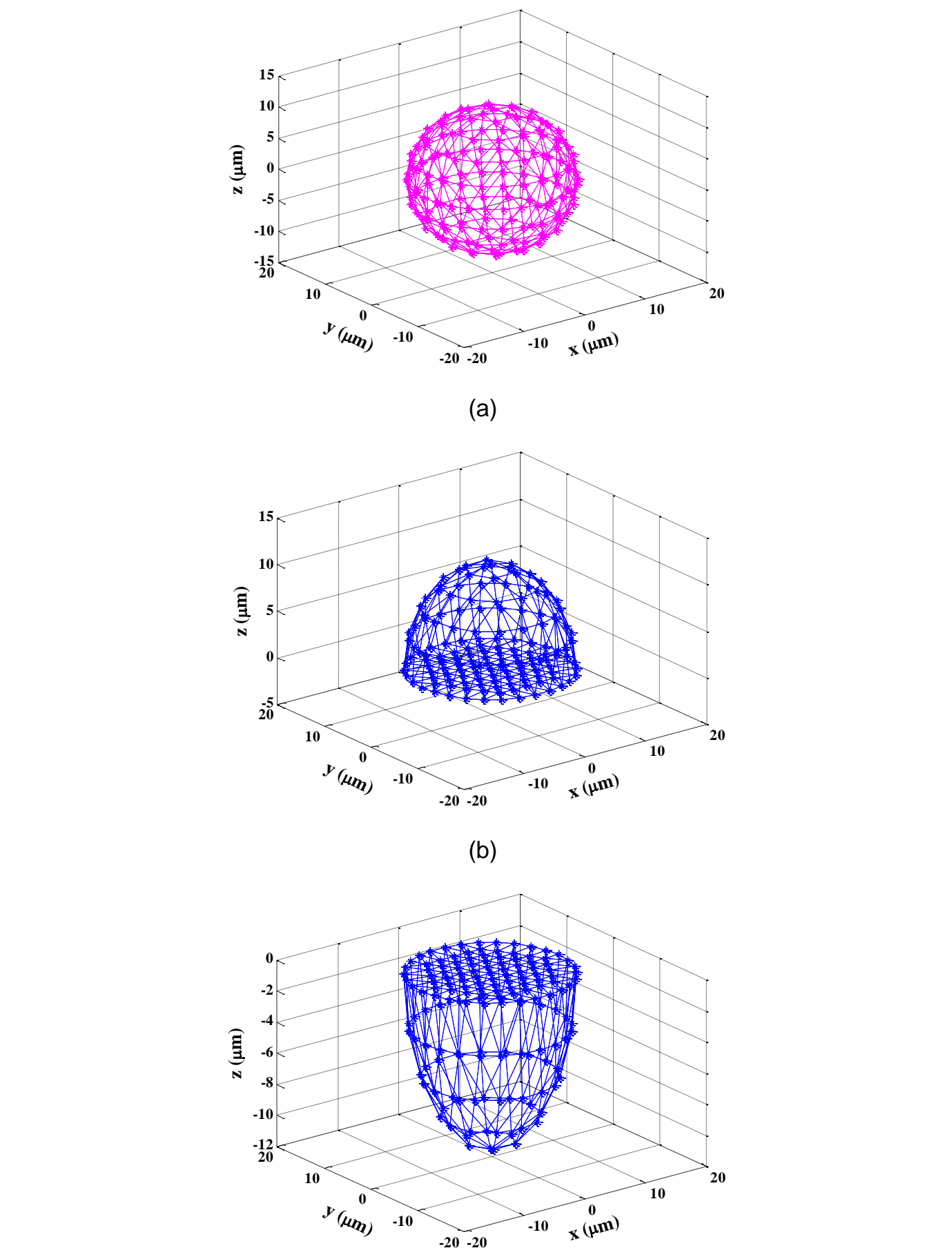

(c)

Figure 1. Physical tumor growth results. (a) the initial tumor cell at the origin, (b-c) two daughter cells of the initial tumor cell after a cell division. 


\subsection{Chemical Modeling Results}

The purpose of the chemical modeling is to solve a set reaction diffusion equations which will help understand the growth mechanism of avascular tumor if we know the quantitative knowledge of its surrouding chemical microenvironment. Then, the parameters of the mouse mammary tumor cells EMT6/Ro were used in our experiment, which were derived from our research partner, the Applied Mathematics and Plasma Physics (T-7) group at Los Alamos National Laboratory. In our experiment, the oxygen and glucose were used as nutrients while the GIF was used as the growth inhibitor factor that produced by a list of proteins on the cell cycle. We assume that the nutrients metabolic rates of quiescent cells are half of that for proliferating cells and the metabolic rates of necrotic cells are 0 . Then, we set the thimor growth time to be 40 days or 320 Monte Carlo steps(MCS), $\sigma=1, \sigma_{0}=10 \wedge 4, \vec{\Gamma}=$ $\left(\Gamma_{0}, \Gamma_{\mathrm{G}}\right)=(1,1), \alpha_{\mathrm{O}}=9 * 10^{\wedge}(-6), \alpha_{\mathrm{G}}=2 * 10^{\wedge}(-8), \alpha_{\mathrm{GIF}}=8 * 10^{\wedge}(-11)$. A tumor spheroid will start from a single cell to a multiscale sturcture fwith a protiferating layer(P), a quiescent layer( $(\mathrm{Q})$ and a necrotic layer( $\mathrm{Q})$ by using the finite element method for avascular growth. We set the simulation time to be 40 days and the initial chemical concentrations $\left(\mathrm{N}_{\mathrm{O}}^{\mathrm{INT}}, \mathrm{N}_{\mathrm{G}}^{\mathrm{INT}}, \mathrm{G}_{\mathrm{GIF}}^{\mathrm{INT}}\right)$ at $(0.08 \mathrm{mM}, 5.5 \mathrm{mM}, 0 \mathrm{mM})$. All the chemieal growthes are simulated by Matlab codes. Figure 2(a-c) showed the distribution map of oxygen concentration at there sampled time, which are 0 day, 10 day and 30 day respectively. The chemical modeling results for the other two chemicals, which are the Glucose and the GIF, are shown in Figure 3 and Figure 4 at the appendix section seperately. The distance refers to the length between the sampled point and the tumor spehroid core. It can be seen that the oxygen as well as gulcose concentration of internal tumor spheroid is lower than that on the tumor spheroid surface, while the concentration of GIF is on the opposite. There are several key stages during a change of oxygen concentration. In the beginning 0-10.5 days, the oxygen concentration drops all the time, accompanied by an increase of tumor radius due to a rapid growth. A constant area of low oxygen concentration which is near the threshold in the center of tumor spheroid is formed after 10.5 days growth and continues to expand until 19.5 days growth when it reaches-maximum value There is a little increase of this low oxygen concentration betwenn 19.5 days and 30 days. After that, the distribution of oxygen concentration reaches a stable status. As another kind of nutrients, the distribution map of glucose shows a similar results as that of oxygen. The differences between these two nutrients lie in the simulation time for such concentration changes. For glucose, 0-13.5 days is its concentration descending stage, 13.5-22.5 days is the formation time for its low concentration ring area, 22.5-31.5 is a period for a liftle increase in this ring area and the distribution of glucose concentration reaches a stables status after that period. In contrast with that of nutrients, the concentration of GIF grows with the simulation time as well as the tumor spheroid radius and there is no such lower or higher constant area. From these three groups of chemical distribution map, we can drawn the conclusion that the oxygen as well as gulcose concentration of internal tumor spheroid is lower than that on the tumor spheroid surface, while the concentration of GIF is on the opposite. 
International Journal of Multimedia and Ubiquitous Engineering Vol.9, No.4 (2014)

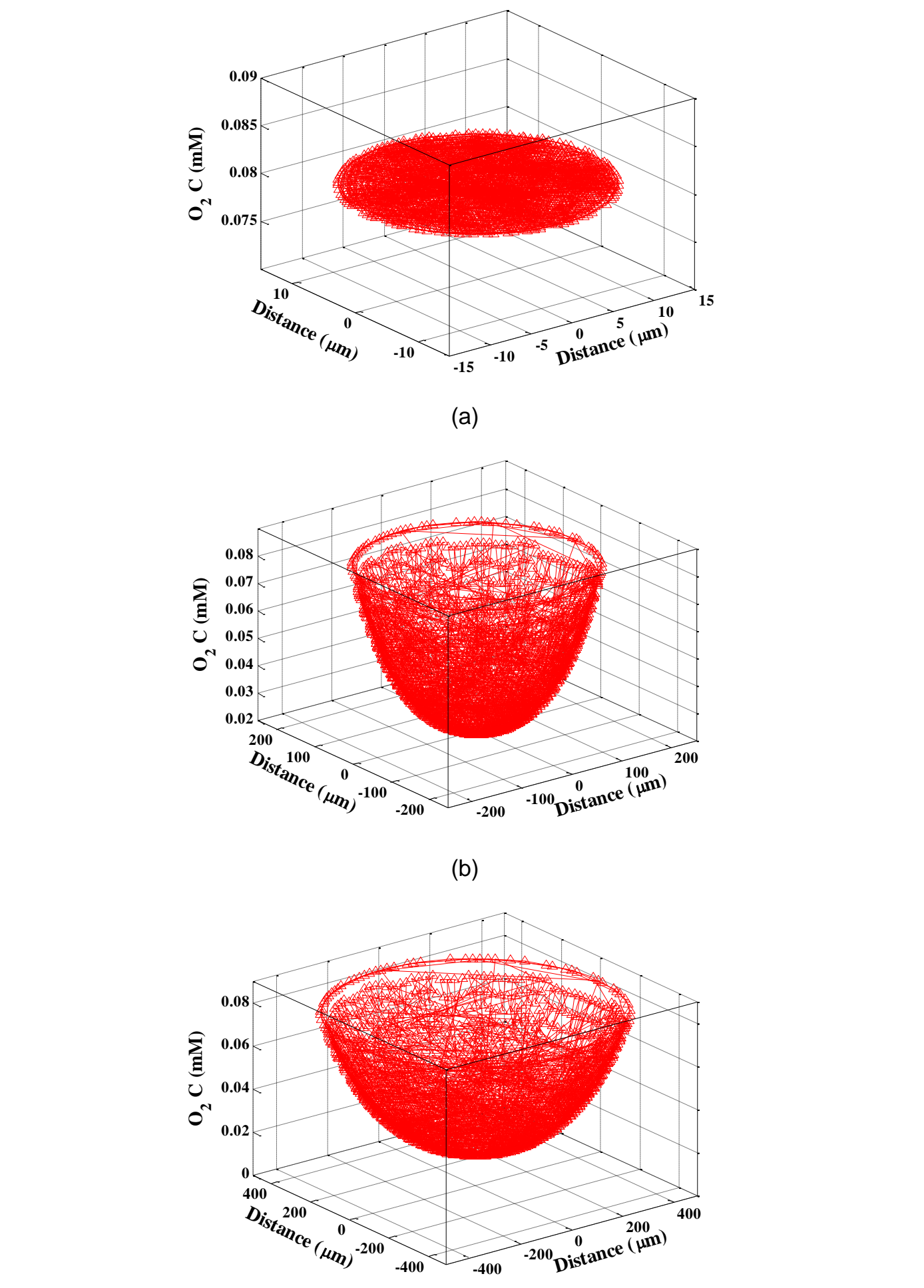

(c)

Figure 2. Oxygen concentration at sampled simulation time, with: (a) 0 day, (b) 10 days, (c) 30 days 


\section{Conclusion}

In this paper, we proposed a FEM based mixture model for avascular tumor growth by incorporating a chemical modeling approach and a physical modeling approach. In chemical modeling section, a set of reaction diffusion equations were described. In physical modeling section, a finite element approach was conducted according to the former constructed finite element equations. In the experiment section, the results showed that our approach achieved a good performance for the growth of the EMT6/Ro mouse mammary tumor cells.

\section{Acknowledgments}

This paper was supported by the National Natural Science Foundation of China under Grant No. 71202165 and the Intelligence Advanced Research Projects Activity (IARPA) yia Department of Interior National Business Center contract number D11PC20068.

\section{References}

[1] J. Holland, R. C. Bast, D. W. Kufe, R. E. Pollok, et al. Section 14. In: Cancer Medicine 5, Canada: BD Decker, (2000).

[2] R. H. Thomlinson and L. H. Gray, "Histological structure of some human lung cancers and the possible implications for radiotherapy", Br. J. Cancer, yol. 9, no.4, (1955), pp.539-549.

[3] A. C. Burton, "Rate of growth of solid tumours As a problem of diffusion", Growth, vol. 30, no. 2, (1966), pp. 157-176.

[4] H. P. Greenspan, "Models for the growth of a-solid tumor by ciffusion", Stud. Appl. Math., vol. 51, no. 4, (1972), pp. 317-340.

[5] J. A. Adam, "Simplified Mathemátical Model of Tumor Gowth", Math. Biosci., vol. 81, (1986), pp. $224-229$.

[6] H. Byrne and M. Chaplain, "Free boundary value problems associated with the growth and development of multicellular spheroids”, European J. Appl. Math., vorl. 8, (1997), pp. 639-658.

[7] J. Holash, P. C. Maisonpierre, et al., "Vessel cooption, regression, and growth in tumors mediated by angiopoietins and VEGF", Sclence, vol. 284, no. 5422, (1999), pp. 1994-1998.

[8] M. Byrne, J. R. King, D. Ly S. McElwain and L. Preziosi, “A two-phase model of solid tumour growth”, Appl. Math. Lett., vol. 16 no. 4, (2003). pp. 567573.

[9] T. Roose, S. . Chapman and P. K. Maini, "Mathematical models of avascular tumour growth", SIAM Rev., vol. 49, no. 2, (2007), pp. 179208.

[10] C. A. Borghi and A. Cristofolini, A hybrid implicit numerical method for the analysis of the magneto-plasma dynamics in a gas discharge" IEEE Trans. Magn., vol. 37, no. 5, (2001), pp. 3401-3404.

[11] M. Neri, C. Anselmi, (M. Cascella, A. Maritan and P. Carloni, "Coarse-grained model of proteins incorporating atomistic detail of the active site", Phys. Rev. Lett., vol. 95, no. 21, (2005).

[12] P. Albuquerque, D. Alemani, B. Chopard and P. Leone, "A hybrid Lattice Boltzmann finite difference scheme for the diffusion equation”, Int. J. Multiscale Comput. Eng., vol. 40, no. 2, (2006).

[13] Y. Jiang, J P. Grbovic, C. Cantrell and J. P. Freyer, "A multiscale model for avascular tumor growth", Biophys. Jol. 89, no. 6, (2005), pp. 3884-3894.

[14] M, Scianna and L. Preziosi. Multiscale Developments of the Cellular Potts Model. Multiscale Model. Sim., vol. 10, no. 2, (2012), pp. 342-382.

[15] A. Y. Bohme, "Multi-Scale Modeling in Morphogenesis: A Critical Analysis of the Cellular Potts Model", PLOS ONE, vol. 7, no. 9, (2012), pp. 1-14.

[16] A. Nakajima and S. Ishihara, "Kinetics of the cellular Potts model revisited", New J. Phys., vol. 13, (2011), pp. 1-9.

[17] S. C. Ferreira, J. M. L. Martins and M. J. Vilela, "Reaction-diffusion model for the growth of avascular tumor”, Phys. Rev. E, vol. 65, no. 2, (2002), pp. 1907-1-1907-8.

[18] L. Q. Tang, Y. Jiang, S. B. Dong, et al., “A finite element model for tumor growth”, In ICMMS, (2008).

[19] C. Y. Liu, S. B. Dong, H. L. Li, B. Lu and A. Hauptmann, "A TPSAC Model and Its Application to Mechanical Cloud Simulation”, Int. J. Secur. Appl., vol. 8, no. 1, (2014), pp. 45-56.

[20] B. Lu, C. Y. Liu and Y. H. Wang, "Discovery of Community Structure in Complex Networks Based on Resistance Distance and Center Nodes", J. Comput. Inf. Syst., vol. 8, no. 23, (2012), pp. 9807-9814.

[21] H. Li, A. Deng, J.i Ren, C. Liu, et al., "A modified biphasic system for the dehydration of D-xylose into furfural using $\mathrm{SO}_{4}{ }^{2-} / \mathrm{TiO}^{2-} \mathrm{ZrO}_{2} / \mathrm{La}^{3+}$ as solid catalyst", Catalysis Today, (2014). 
[22] H. J. Wang, X. J. Zou, C. Y. Liu, et al., "Study on Behavior Simulation for Picking Manipulator in Virtual Environment Based on Binocular Stereo Vision", In ICSC, (2008), pp. 27-31.

[23] J. X. Chen, H. J. Wang, C. Y. Liu, et al., "Modeling and Performance Analyzing of Helix Transmission Base on Modelica", Key Eng. Mater., vol. 455, (2011), pp. 511-515.

[24] H. Li, A. Deng, J. Ren, C. Liu, et al., "Catalytic hydrothermal pretreatment of corncob into xylose and furfural via solid acid catalyst”, Bioresource Technology, vol. 158, (2014), pp. 313-320.

[25] H. J. Wang, J. X. Chen, X. J. Zou and C. Y. Liu, "Structure design and multi-domain modeling for a picking banana manipulator”, Adv. Mater. Res., vol. 97-101, (2010), pp. 3560-3564.

[26] H. J. Wang, X. J. Zou, C. Y. Liu, et al., "Study on a Location Method for Bio-objects in Virtual Environment Based on Neural Network and Fuzzy Reasoning", In ICIRA, vol. 5928, (2009), pp. 1004-1012.

[27] H. L. Li, S. Y. Wang, W. J. Wang, J. L. Ren, et al., "One-Step Heterogeneous Catalytic Process for the Dehydration of Xylan into Furfural", BioResources, vol. 8, no. 3, (2013).

[28] C. Y. Liu, H. J. Wang, J. X. Chen and X. J. Zou, "Research on Service-Oriented and HLA-Based Simulation Model of Juice Production Line”, In ICMTMA, vol. 3, (2010), pp. 167-170.

[29] J. J. Zhuang and Q. Liu, "Nighttime pedestrian detection method for driver assistance systems", J. South China Univ. Tech., vol. 40, no. 8, (2012), pp. 56-62.

\section{Appendix}

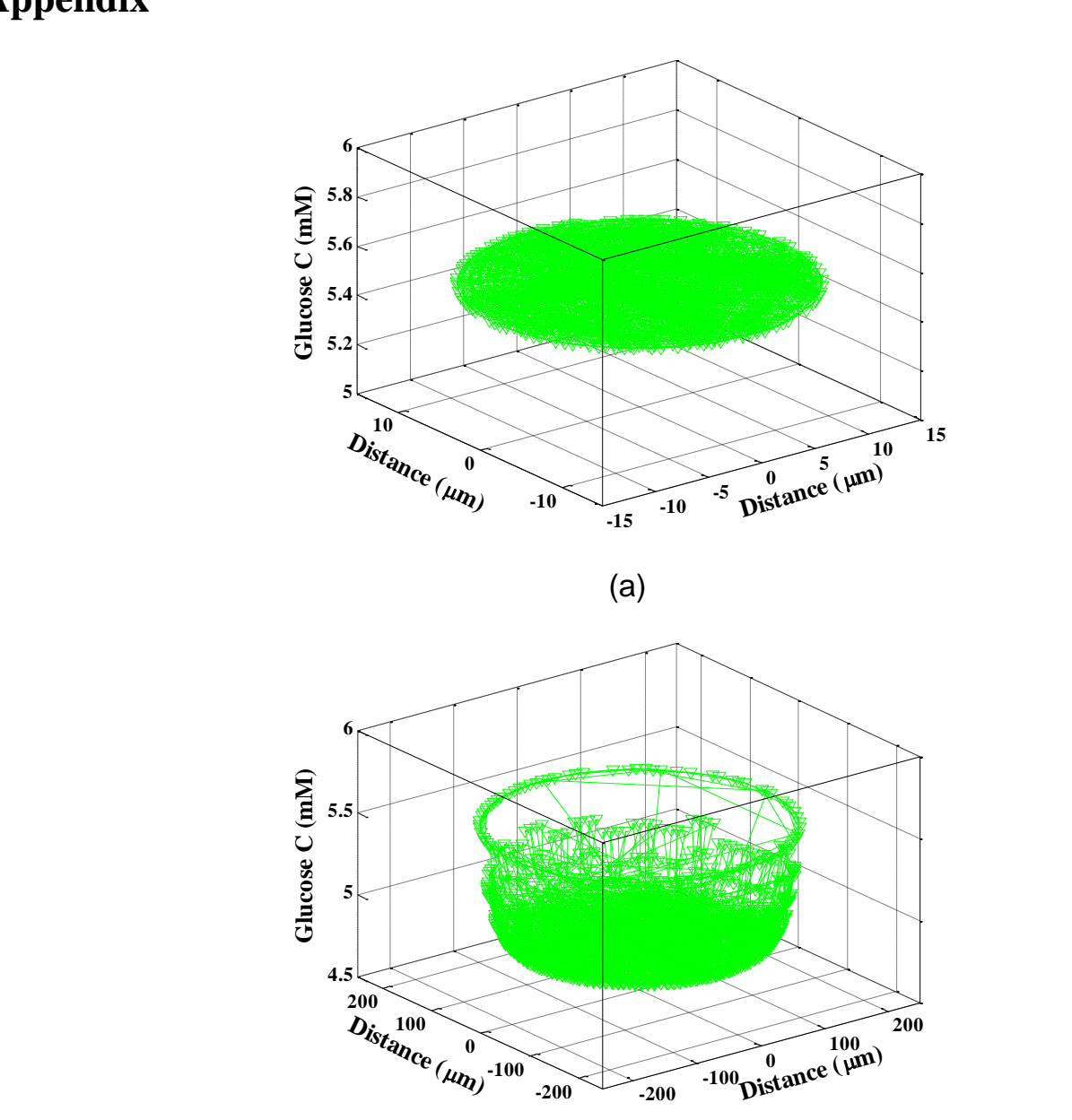

(b) 


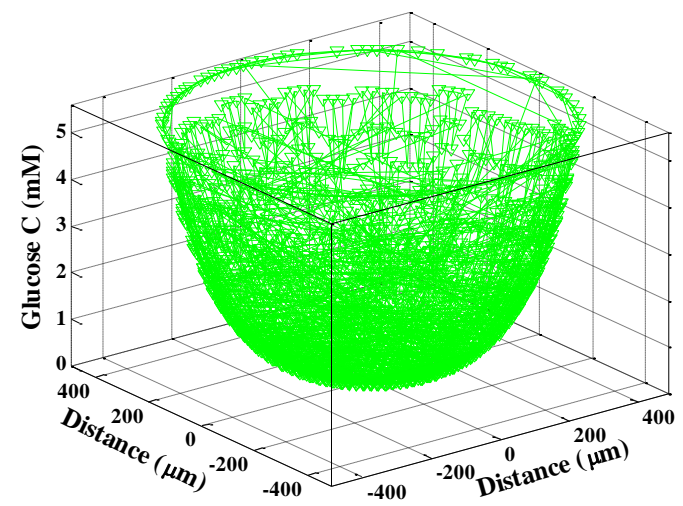

(c)
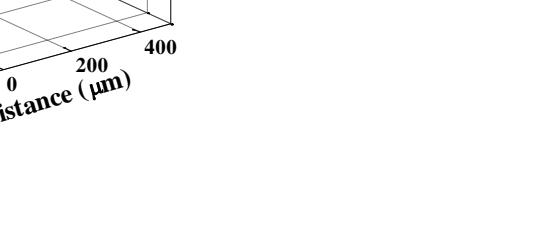

Figure 3. Glucose concentration at sampled simulation time, with: (a) 0 day, (b)10 days, (c) 30 days

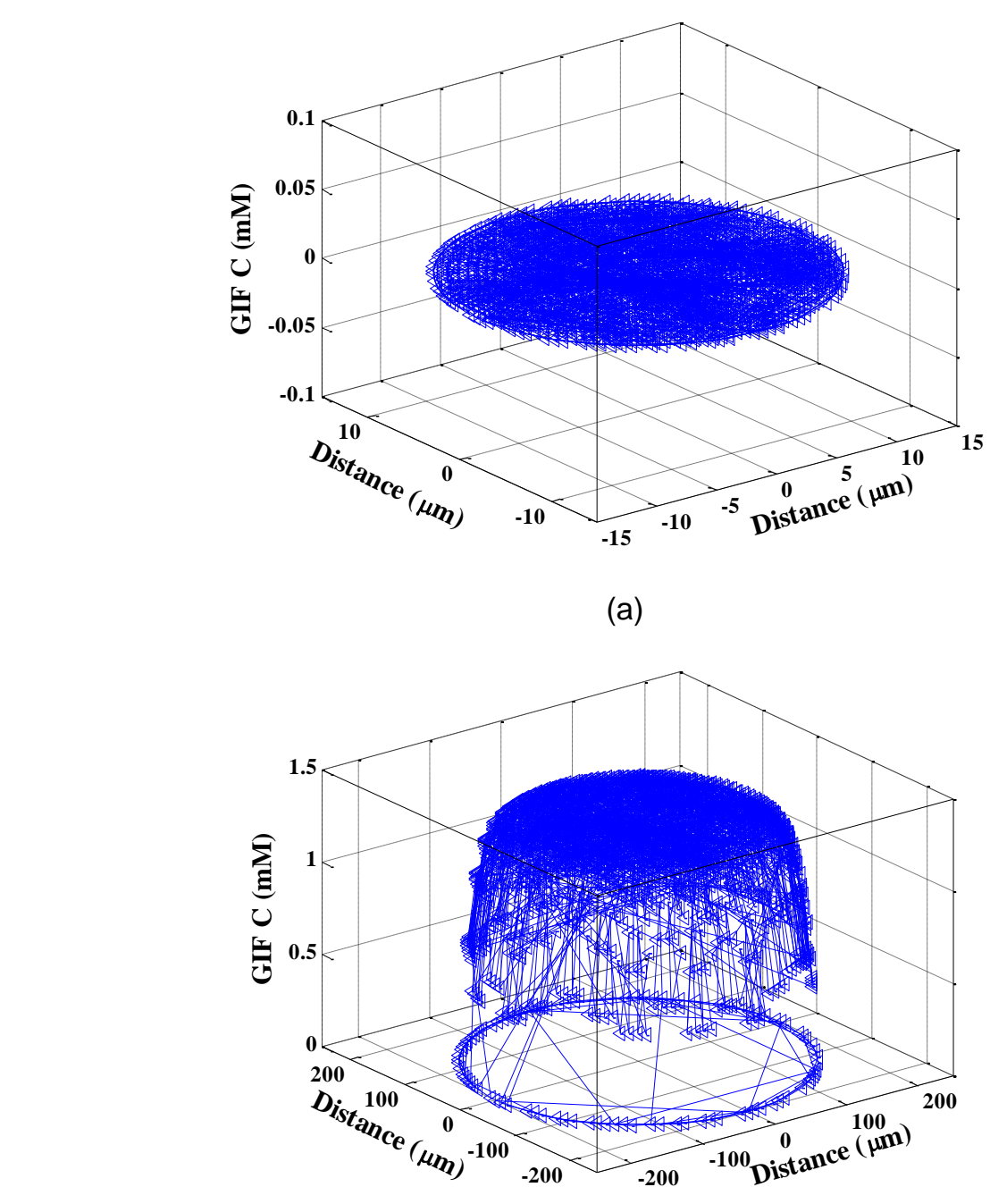


(b)

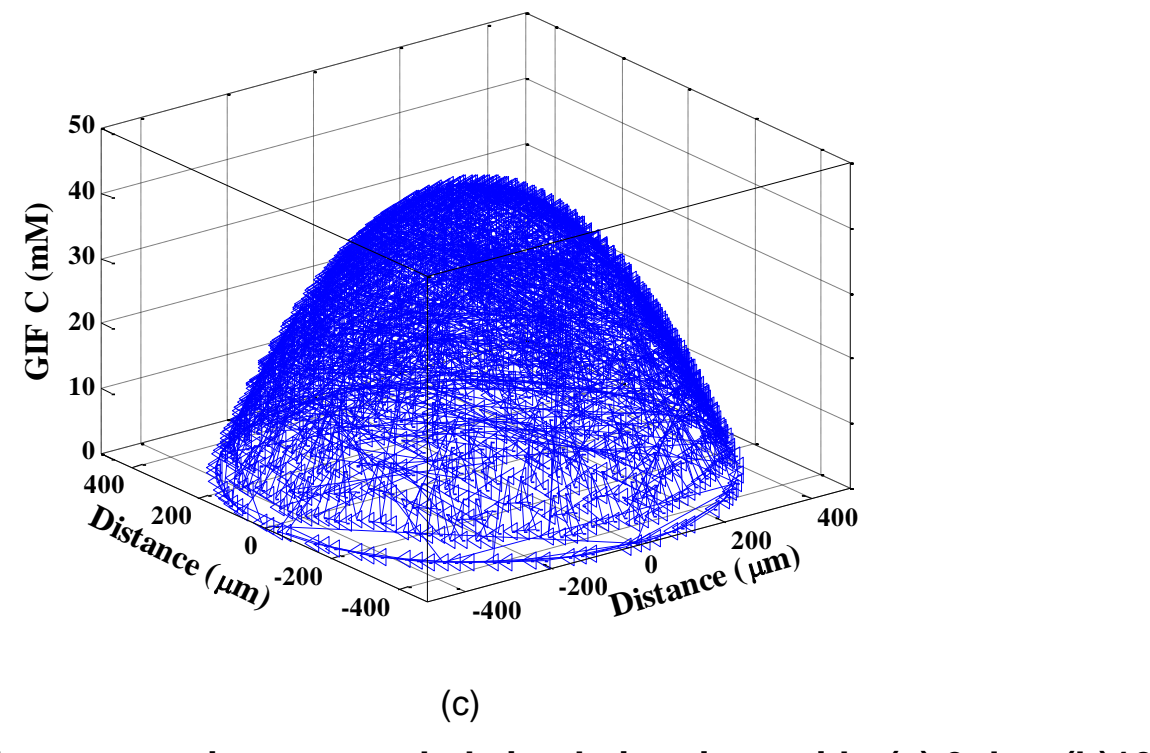

Figure 4. GIF concentration at sampled simulation time, with: (a) 0 day, (b)10 days, (c) 30 days
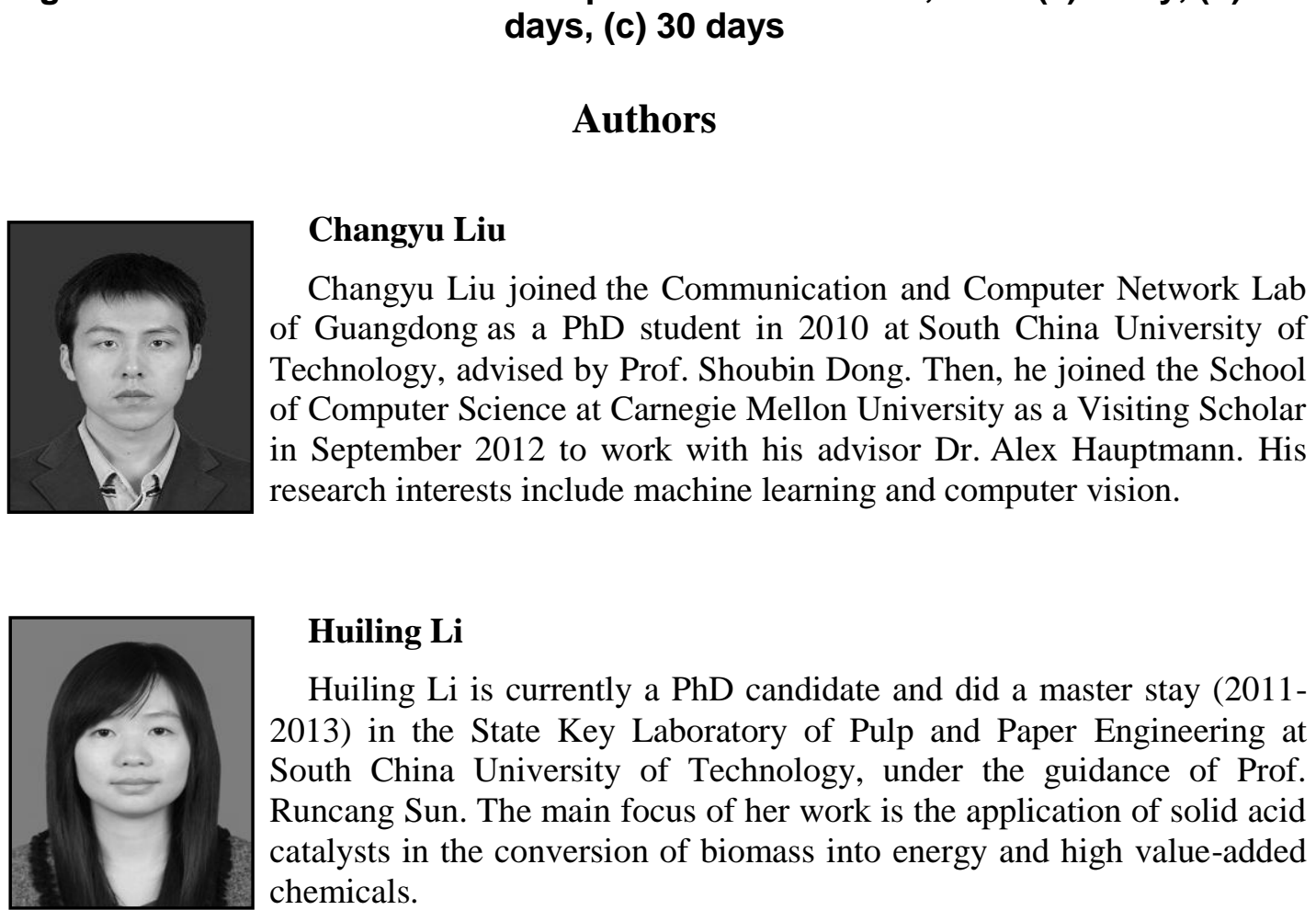

\section{Huiling Li}

Huiling Li is currently a $\mathrm{PhD}$ candidate and did a master stay (20112013) in the State Key Laboratory of Pulp and Paper Engineering at South China University of Technology, under the guidance of Prof. Runcang Sun. The main focus of her work is the application of solid acid catalysts in the conversion of biomass into energy and high value-added chemicals. 


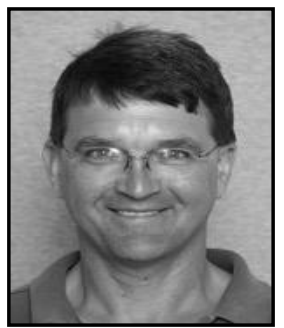

\section{Alex Hauptmann}

Alex Hauptmann is currently a Principal Systems Scientist in the School of Computer Science at Carnegie Mellon University. He has been the leader of the Informedia Digital Library and a founder of the international advisory committee for TRECVID. He received a BA and a MA in Psychology in 1982 from the Johns Hopkins University. He received a $\mathrm{PhD}$ in Computer Science from the Carnegie Mellon University in 1991. His research interests are in multimedia analysis and indexing, speech recognition, interfaces to multimedia system and language in general.

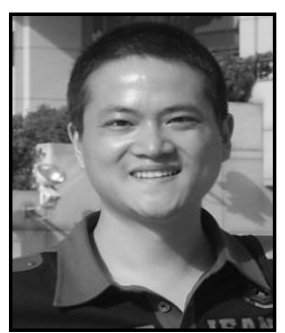

\section{Cong Li}

Cong $\mathrm{Li}$ received the $\mathrm{PhD}$ degree in Management Science and Engineering from Hefei University of Technology in 2009. He is an associate professor at the College of Computer Science, Sichuan Normal University. His research interests include e-commerce and business intelligence. He is a member of the $\mathrm{ACM}$ and the China Computer Federation.

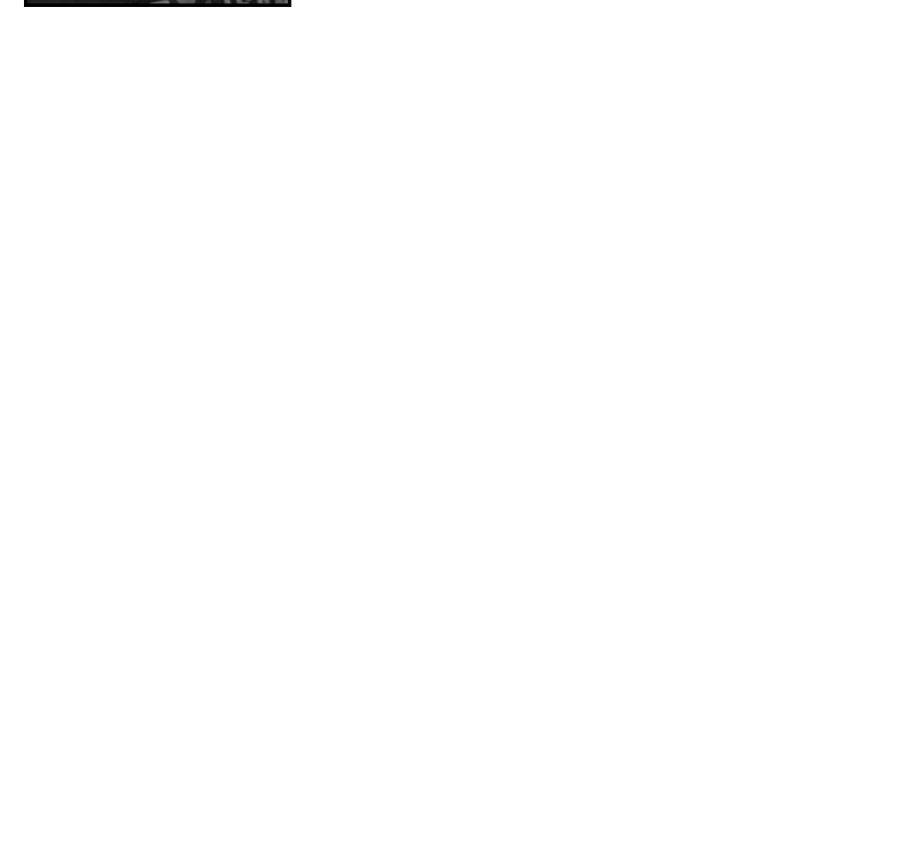


International Journal of Multimedia and Ubiquitous Engineering Vol.9, No.4 (2014)

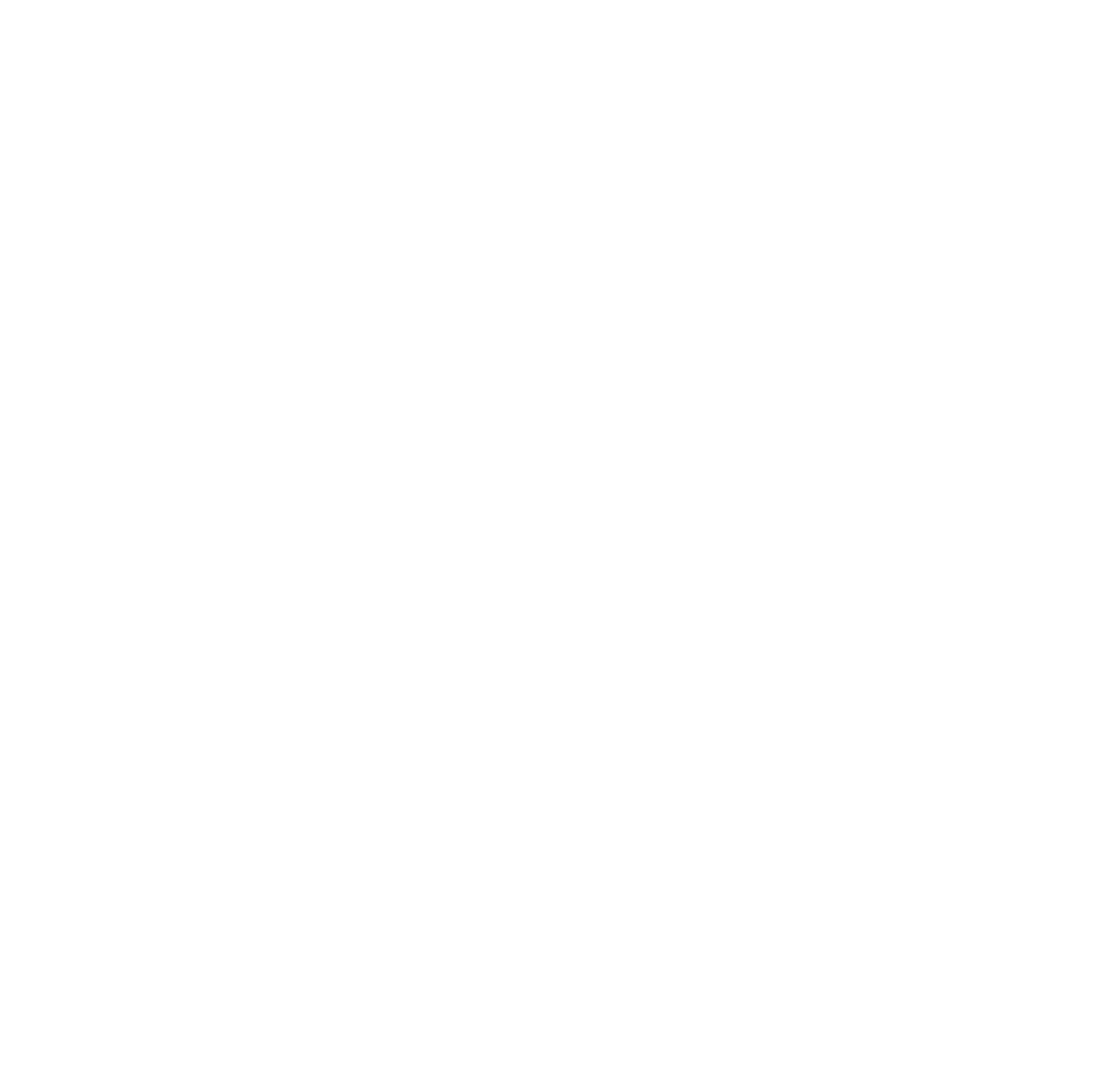

